\title{
Ensino de Ciências por Investigação e o Desenvolvimento de Práticas: Uma Mirada para a Base Nacional Comum Curricular
}

\section{Inquiry-based Science Teaching and the Development of Practices: A Glance to Brazilian National Curriculum}

\section{Lúcia Helena Sasseron Brasil}

Neste artigo, apresentamos e discutimos o ensino de ciências em que os estudantes possam desenvolver sua autonomia intelectual, sendo agentes ativos do processo de aprendizagem, reconhecendo conhecimentos e características da atividade científica. Para tanto, construímos um panorama da atividade científica a partir da discussão de trabalhos de sociologia das ciências. Como decorrência, analisamos estudos da área de pesquisa em ensino de ciências que tratam do papel das práticas científicas e epistêmicas para a promoção da alfabetização científica. Estes estudos fundamentam a análise do documento curricular de Ciências da Natureza presente na recém-publicada Base Nacional Comum Curricular. Ao final, apresentamos impressões sobre elementos que precisam ser considerados para a efetiva concretização dos pressupostos deste documento em sala de aula.

Palavras-chave: Ensino de ciências por investigação; práticas científicas e epistêmicas; Base Nacional Comum Curricular.

This manuscript presents a perspective of science education in which students can develop their intellectual agency, being agents of the learning process, by the recognition of scientific knowledge and the characteristics of scientific activity. To do so, we constructed a panorama of scientific activity from the discussion of studies from sociology of science. As a result, we analyze studies in science education that deal with the role of scientific and epistemic practices for the promotion of scientific literacy. These studies base the analysis of the curricular document of Natural Sciences included in the recently published Brazilian National Curriculum Standards. At the end, we present impressions about elements that need to be considered for the effective realization of this documents assumptions in classrooms.

Keywords: Inquiry-based Science teaching; scientific and epistemic practices; Brazilian National Curriculum Standards. 


\section{A sala de aula e as práticas}

Entre em uma escola, acomode-se em uma sala de aula e assista por alguns momentos as aulas que ali se desenvolvem. Há uma dinâmica própria estabelecida neste espaço por meio da qual professores e alunos interagem. A distribuição espacial dos móveis, pessoas e objetos interfere nesta dinâmica, assim como os papeis desempenhados pelos diferentes atores que transitam por este espaço. Há também regras e normas propostas ou tácitas que devem ser seguidas pelas pessoas que ali estão. Intrinsecamente relacionadas, as regras e normas influenciam diretamente na dinâmica das interações e podem ser alteradas, excluídas ou acrescentadas a depender da maneira como as ações ocorrem neste espaço escolar.

Livros, cadernos, figuras penduradas nas paredes, slides exibidos em projeção são exemplos de materiais existentes e que são utilizados com maior ou menor frequência em diferentes aulas. O professor apresenta os temas de sua disciplina, tira dúvidas dos estudantes, propõe tarefas e os ajuda a resolvê-las; constantemente, de forma sistematizada ou não, avalia o desempenho de seus estudantes. Alunos tomam nota do que parece a eles importante da fala do professor; registram o que o docente solicita que seja anotado; respondem a questionamentos a eles direcionados; trabalham em grupo ou sozinhos a depender do comando recebido.

Claro que há situações outras, extremas, em que esta dinâmica não se dá conforme o descrito acima. Rapidamente exemplos destas situações surgem em nossa mente, representados pelos casos de indisciplina e de desrespeito. Mas nem toda quebra da dinâmica ordenada e aparentemente eficiente representa um problema para o estabelecimento de uma boa relação entre as ações de ensino e de aprendizagem. E é bastante possível que a constituição perene desta dinâmica não seja uma virtude para o êxito do ensino. Há mais a se ensinar do que aquilo que o professor é capaz de apresentar e reproduzir em quadros, esquemas, slides e lousas e há mais a se aprender do que aquilo que os alunos registram em suas memórias, em seus cadernos e reconhecem como dúvidas no instante em que tomam contato com o novo tema.

Os campos disciplinares que são ensinados na escola advêm de áreas de conhecimento consolidadas na sociedade. Cada qual representa não somente uma lista de temas que estão sob seu olhar mais atento, mas também modos de construir conhecimento, de analisá-lo, avaliá-lo e torná-lo legitimado nesta comunidade e por ela. Tomadas deste modo, as disciplinas escolares são, portanto, organizações de conhecimento que servem para auxiliar o trabalho didático e pedagógico. Seguindo esta lógica, cada disciplina possui sua própria cultura e sua própria epistemologia, podendo as diferentes disciplinas escolares assemelharem-se em alguns aspectos, mas sendo singulares quando comparadas entre si. Para Young (2007), estas disciplinas escolares precisam evidenciar suas fronteiras e delimitá-las também na relação com conhecimentos trazidos pelos estudantes e oriundos da experiência cotidiana; sendo papel da escola o desenvolvimento intelectual dos estudantes por meio das suas disciplinas.

Estudioso das disciplinas escolares, Chervel (1990) analisa o surgimento e o uso 
do termo em uma perspectiva histórica e o relaciona à ideia de "ginástica intelectual", apresentando uma concepção educacional que congrega corpo e intelecto. Para ele, uma disciplina é "um modo de disciplinar o espírito, quer dizer de lhe dar os métodos e as regras para abordar os diferentes domínios do pensamento, do conhecimento e da arte" (1990, p.180). A partir destes fundamentos, Chervel questiona o papel que a disciplina pode representar no trabalho pedagógico e, diante disso, surgem suas inquietações acerca das contribuições na formação do sujeito. Não é intuito de Chervel discorrer sobre as especificidades de cada uma das disciplinas que possam compor um currículo.

De maneira comedida, pretendemos enveredar por esta discussão neste presente texto. Nosso objetivo é analisar como as ciências figuram no novo documento curricular nacional, a Base Nacional Comum Curricular ${ }^{1}$, e, com base nisso, discutir como o trabalho em sala de aula pode contribuir para o ensino de ciências que realmente introduza as ciências como corpo de conhecimento nas salas de aula.

Para atingir este objetivo, nas próximas páginas apresentaremos discussões teóricas que fundamentam nossa percepção da atividade científica como o desenvolvimento de práticas e a análise destas para o ensino de ciências; em sequência, apresentaremos elementos que constituem a BNCC e prosseguimos a uma breve análise sobre o componente curricular Ciências da Natureza conforme ali apresentado.

\section{Ciência e práticas}

A atividade científica tem sido estudada por filósofos, epistemólogos, historiadores e sociólogos. Muitas são visões que se têm sobre as ciências e a atividade científica. Elas provêm da análise do trabalho dos cientistas por diversos métodos e revelam pontos de vista em que, cada qual a sua maneira, sustentam visões sobre o papel do experimento, de equipamentos, dos tipos de raciocínio, das teorias, dos cientistas, das comunidades e de outros agentes e atores que participam do desenvolvimento das ciências.

Neste estudo, optamos por pautar nossas observações em proposições trazidas por pesquisadores que analisam a atividade científica em uma perspectiva sociologizada. Isso quer dizer que não se trata de um estudo sociológico das ciências, mas de um olhar para a atividade científica tomando-a como atividade social, pautada em normas e regras que influenciam em seu desenvolvimento (Knorr-Cetina, 1999, Longino, 1990, 2002, Pickering, 1992).

Um estudo pioneiro para a discussão da atividade científica como uma atividade social encontra rudimentos nos resultados obtidos por Latour e Woolgar (1986) a partir das análises das observações realizadas pelo primeiro pesquisador quando de sua estadia de aproximadamente um ano em um laboratório voltado aos estudos de neuroendocrinologia.

Acompanhando as atividades diárias que eram realizadas pelas pessoas que

1 O documento utilizado como referência é a versão aprovada pelo Conselho Nacional de Educação, em dezembro de 2017, e publicado no site do MEC - Ministério da Educação, em 20 de dezembro do mesmo ano. A versão digital pode ser encontrada em http://basenacionalcomum.mec.gov.br 
estavam naquele espaço, registrando similaridades e surpresas nos objetos, nas informações e nos usos dos mesmos durante as diferentes atividades realizadas pelas pessoas que trabalhavam no laboratório, Latour e Woolgar (1986) apresentam características que revelam modos de trabalho para a construção de fatos científicos. De modo geral, descrevem e discutem os processos realizados para obtenção, produção e construção de entendimentos sobre inscrições literárias; e isso está intimamente relacionado à realização de práticas para obtenção de novas informações, seja por meio de experimentos ou por consulta a outros estudos, trabalho com novas informações, revisão de informações, construção de explicações e sistematização das mesmas. Podemos entender que tais práticas permitem a proposição de novos conhecimentos.

Com o intuito de analisar como novos conhecimentos passam por processos que lhes garanta a objetividade, Longino $(1990,2002)$ ressalta o papel da comunicação das ideias em ciências, alegando que a comunicação é uma característica de uma comunidade e não de um indivíduo. Conforme esta pesquisadora "as interações discursivas críticas são processos sociais de produção de conhecimento" (Longino, 2002, p.129).

$\mathrm{Na}$ discussão de aspectos da investigação científica que a levem a respostas sobre como surgem e se relacionam valores e objetividade em ciências, Longino (2002) parte da percepção de que a "investigação científica é uma atividade humana colaborativa" (p. 17). E, apoiando-se em trabalhos de Grene e MacIntyre ${ }^{2}$, para Longino, a atividade científica é uma prática. Para isso, usa o conceito de prática apresentado por MacIntyre:

"qualquer forma coerente e complexa socialmente estabelecida de atividade humana cooperativa através da qual produtos internos para esta forma de atividade são efetuados na tentativa de alcançar padrões de excelência que são apropriados e característicos dessa forma de atividade" (1981, citado em Longino, 1990, pp.17-18).

Apesar de apropriar-se desta definição de prática, Longino (1990) faz questão de frisar que modificações no modo de entender a prática científica teriam que ser realizadas. Ainda assim, tal definição aponta para a influência do social em práticas humanas.

Estas ideias permitem que Longino (1990) estabeleça suas ideias de investigação científica como algo "social e complexo, compreendendo muitas atividades desempenhadas por diferentes pessoas" e que "devemos aceitar que diferentes concepções de conhecimento podem se desenvolver no contexto de diferentes práticas ou supor que há algum subconjunto de práticas pertencente a todas as práticas de produção de conhecimento" (p.19). Para ela, a investigação científica produz teorias, mas também, e ao longo dos processos, promove interações de naturezas distintas que se integram e se transformam, sendo, portanto, advindas de negociações sociais. Sua ideia de ciência como prática e, em decorrência, praticada por grupos sociais é o que confere a ela objetividade.

2 Para esta discussão, não tivemos acesso aos textos destes dois autores usados por Longino. Segundo consta nas referências bibliográficas citadas por Longino, trata-se das obras: The knower and the known, de Marjorie Grene, edição de 1966, e After Virtue, de Alasdair MacIntyre, edição de 1981. 
As práticas realizadas na atividade científica e que permitem a constituição de objetividade para o conhecimento proposto ocorrem, como indica Longino (1990), pelas interações sociais entre os indivíduos que atuam em um mesmo local, com outros sujeitos e com conhecimentos produzidos por outros pesquisadores e técnicos de outros grupos de pesquisa. Estas interações ocorrem regidas por "normas sociais do conhecimento social" descritas por Longino (2002) como os fóruns de discussão, a disposição e aceitação à crítica, a existência de padrões públicos de conhecimentos e a constituição de igualdade moderada ${ }^{3}$. Tais normas garantem o desenvolvimento de práticas de produção, comunicação, avaliação e legitimação de conhecimentos (Kelly, 2008).

As ideias anteriormente expostas advindas dos trabalhos de Latour e Woolgar (1986) e de Longino (1990, 2002) explicitam a exploração, a investigação e a crítica que caracterizam as ciências e, por este motivo, ajudam-nos neste olhar para a atividade científica como o desenvolvimento de práticas.

Podemos perceber que as práticas delineadas por Latour e Woolgar (1986) representam ações voltadas mais diretamente ao trabalho para construção de entendimento sobre um fenômeno. A proposta de Longino (2002), por sua vez, representa a análise de elementos que configuram esta construção e se mesclam às práticas realizadas neste momento. Entendemos que seja possível utilizar estas ideias para analisar o ensino de ciências seja em seu planejamento ou na implementação, com foco no currículo prescrito ou construído ou nas estratégias e abordagens desenhadas. De todo modo, aproximações precisam ser feitas e as discutiremos a seguir.

\section{As práticas e o ensino de ciências}

Retomemos a situação apresentada no início deste texto sobre nossa inserção em uma sala de aula de uma escola brasileira. Com raras exceções, o panorama que encontramos são salas de aula em que as lições de Língua Portuguesa, Matemática, História, Geografia, Ciências e de todas as demais disciplinas pouco se diferem entre si para além dos conteúdos que são apresentados aos estudantes. Invariavelmente, as aulas acontecem como descrito anteriormente: o professor apresenta o tema, exemplifica, tira dúvidas e propõe atividades de fixação e os estudantes anotam e respondem aos pedidos do docente. Muito pouco (ou quase nada) há nas diferentes aulas de elementos que caracterizam a área de conhecimento que deu origem às disciplinas escolares. Em outras palavras, muito pouco é explorado, em sala de aula, sobre práticas e normas que caracterizam uma área de conhecimento e a abordagem das disciplinas fica restrita aos tópicos conceituais que a constituem.

Não é recente a ideia de que o ensino das disciplinas deva ocorrer por meio de um papel ativo dos estudantes. As primeiras menções a esta proposta encontram respaldo nos ideais de John Dewey (1971) e no destaque que oferece à relação entre

3 No original em inglês, as normas sociais para o conhecimento social são apresentadas como venue, uptake, public standards e tempered equality. 
ensino e práticas cotidianas assim como ao papel de interações sociais nos processos de construção de conhecimento.

Especificamente ao ensino de ciências, durante um bom período, a partir da primeira metade do século XX, a ideia de hands on, caracterizando um ensino por descoberta, orientando por etapas descritas e previamente definidas, revelava a ênfase nos procedimentos e no desenvolvimento de ações. Mais recentemente, a alteração de foco mostra a preocupação em relacionar o desenvolvimento de procedimentos com a aprendizagem conceitual e a crítica assume papel central no processo de investigação em sala de aula (Duschl, 2008, Ford, 2015, Jiménez-Aleixandre e Crujeiras, 2017, Osborne, 2016, Stroupe, 2014, Windschitl et al, 2008, entre outros). Esta mudança de foco no ensino de ciências para o trabalho com o desenvolvimento de práticas tem sido cada vez mais abordada nas pesquisas em todo o mundo e começa a figurar nos currículos escolares ${ }^{4}$.

Relacionado a isso, nos dias atuais, tem se tornado grande preocupação a conferência de autoridade intelectual aos estudantes em situações de ensino ${ }^{5}$ (Berland, \& Hammer, 2012, Carvalho, 2013, Duschl, 2008, entre outros). Tal autoridade intelectual prevê a participação dos estudantes nas discussões estabelecidas em sala de aula, e também considera a importância de fomentar ações e práticas que culminem com o desenvolvimento de modos de raciocinar e de construir juízo sobre questões e formas realizar investigações críticas sobre problemas do dia a dia. Estas ideias também fundamentam as bases da alfabetização científica, uma vez que esta é entendida como a possibilidade de os indivíduos construírem entendimento sobre situações de sua vida, que envolvam conhecimentos de ciências, por meio de processos de investigação e uso de análise crítica (Bybee, \& DeBoer, 1994, Hurd, 1998, Fourez, 1994).

O desenvolvimento das práticas em sala de aula, em nosso entendimento, deve considerar aquilo que é próprio das ciências. Por isso, e por serem sociais, as práticas têm características diversas que, segundo Kelly (2008), são "um conjunto padronizado de ações, normalmente realizadas pelos membros de um grupo baseadas em objetivos e expectativas comuns e de acordo com valores, ferramentas e significados culturais" (p.99). Dois principais tipos têm sido tratados de modo mais detido nas pesquisas da área: as práticas científicas e as práticas epistêmicas. Embora estes dois tipos de práticas sejam utilizados concomitantemente, de forma colaborativa e mútua, é possível distingui-los teoricamente.

Concordando com Kelly (2008) que práticas são sociais, Jiménez-Aleixandre e Crujeiras (2017) propõem as práticas epistêmicas e práticas científicas como construtos amplos. Na intersecção entre ambas, surgiriam práticas epistêmicas do contexto de uma

\footnotetext{
4 Apenas a título de exemplo, os parâmetros curriculares norte-americanos para o ensino de ciências, NGSS - Next Generation of Science Standards, organizam os temas em três dimensões de aprendizagem: ideias disciplinares centrais, conceitos transversais e práticas das ciências e da engenharia (no original, respectivamente, disciplinary core ideas, crosscutting concepts e science and engineering practices).

5 Ainda que esta possa ser uma realidade associada às demais disciplinas, não nos preocupamos em realizar este levantamento, uma vez que o foco deste artigo é o ensino de ciências.
} 
disciplina de ensino específica. No caso do ensino de ciências, estas práticas seriam a investigação, a avaliação ${ }^{6}$ e o desenvolvimento de explicações. As pesquisadoras ainda mencionam que, no ensino de ciências, as práticas se associam a atividades nas quais é esperado que os estudantes se engajem de modo a construir modelos explicativos.

Uma interpretação que fazemos da proposta de Jiménez-Aleixandre e Crujeiras (2017) sobre o desenvolvimento de práticas científicas e epistêmicas no contexto das aulas de ciências traz à tona um outro cenário: em sendo desenvolvidas apenas as práticas científicas na sala de aula, os estudantes podem reproduzir ações de modo irrefletido e, portanto, realizar etapas como se um roteiro prévio estivesse estabelecido e não fosse preciso entende-lo ou mesmo questioná-lo. A promoção e a constatação de desenvolvimento de práticas epistêmicas em sala de aula podem marcar o advento da reflexão sobre as ações realizadas e eventuais mudanças no que está sendo feito, sinalizando liberdade intelectual conferida aos estudantes e assumida por eles.

O trabalho com as práticas também tem se tornado cada vez mais frequente nas pesquisas em ensino de ciências e alguns destes estudos referem-se diretamente à análise de propostas curriculares (Ford, 2015, Stroupe, 2015, Osborne, 2014, Duschl, 2008).

Tendo assumido as ideias anteriormente expostas, na busca por entender melhor como estas práticas podem surgir e se desenvolver em salas de aula, damos atenção às práticas científicas a partir do estudo de Latour e Woolgar (1986) e às práticas epistêmicas pelos trabalhos de Longino $(1990,2002)$.

Trabalhos anteriores desenvolvidos em nosso grupo de pesquisa do LaPEF Laboratório de Pesquisa e Ensino de Física da FEUSP - permitem-nos propor práticas científicas realizadas em aula de ciências como sendo: o trabalho com novas informações; o levantamento e o teste de hipóteses; e a construção de explicações, a elaboração de justificativas, limites e previsões das explicações (Sasseron, \& Carvalho, 2008, 2011). Estas práticas representam ações para o a investigação, a avaliação e o desenvolvimento de explicações, tal qual proposto em Jiménez-Aleixandre e Crujeiras (2017) como parte das práticas do contexto da disciplina de ciências.

Com relação às práticas epistêmicas para o ensino de ciências, utilizamos aqui as ideias já consolidadas e apresentadas por Kelly (2008), reconhecendo que elas se associam à proposição, comunicação, avaliação e legitimação de ideias.

Assim, as práticas científicas representam ações direcionadas à resolução de problemas, enquanto as práticas epistêmicas associam-se a aspectos metacognitivos da construção de entendimento e de ideias sobre fenômenos e situações em investigação. Isso nos leva a retornar uma vez mais ao trabalho de Jiménez-Aleixandre e Crujeiras (2017) sobre a ocorrência, muitas vezes concomitante e complementar das práticas científicas e das práticas epistêmicas. Em sala de aula de ciências, seria muito importante que esta ocorrência conjunta fosse cada vez mais frequente, de modo a evitar que as práticas fossem realizadas de modo irrefletido, mecânico.

6 Avaliação, neste caso, é o processo por meio do qual ideias são analisadas. Não se refere à avaliação do ensino e da aprendizagem. 
Acreditamos que a identificação conjunta destas práticas pode potencializar o desenvolvimento da alfabetização científica, considerada como um objetivo do ensino de ciências voltado a que os sujeitos possam conhecer as ciências, reconhecer os modos como as ciências entendem os fenômenos, utilizar esses modos de estruturar ideias e pensamentos para a análise de fenômenos e de situações a eles relacionadas e tomar suas decisões (quaisquer que sejam) considerando tais aportes.

\section{O desenvolvimento de práticas: o papel do ensino por investigação}

Temos defendido, com base em outras pesquisas, que o ensino por investigação pode ser um modo apropriado para que a alfabetização científica ocorra em sala de aula (Freiberg, 2015, Sasseron, \& Carvalho, 2008, Solino, 2017, Souza, 2015, entre outros). Consideramos que o ensino por investigação é uma abordagem didática (Sasseron, 2015, Solino, 2017), pois não está associado a estratégias específicas, mas às ações e às práticas realizadas pelo professor quando da proposição dessas estratégias e tarefas aos estudantes, sendo essencial o estabelecimento de liberdade intelectual aos alunos para a investigação de um problema (Carvalho, 2013).

Nossa concepção de ensino por investigação está fundamentada em resultados de pesquisas da área de ensino de ciências, mas também nas ideias propostas por Dewey (1971), em especial aquelas que marcam o papel da experiência nos processos educativos, e por Freire (1967), com destaque para as transformações culturais e sociais que decorrem da educação. Deste modo, consideramos cinco principais elementos que se fundem para a ideia de ensino por investigação que utilizamos: o papel intelectual e ativo dos estudantes; a aprendizagem para além dos conteúdos conceituais; o ensino por meio da apresentação de novas culturas aos estudantes; a construção de relações entre práticas cotidianas e práticas para o ensino; a aprendizagem para a mudança social.

Em suas primeiras discussões, o ensino por investigação esteve associado à ideia de hands on, o que revela ênfase no cumprimento de etapas de um roteiro descritivo de ações para a conclusão de uma atividade. Em outras palavras, o ensino baseava-se, essencialmente, no desenvolvimento de conhecimento de processos. Uma alternância ao destaque sobre os processos adveio a partir da percepção de que os mesmos não devem ser realizados apenas como ações práticas, sendo importante o desenvolvimento do conhecimento conceitual em conjunto com o desenvolvimento do conhecimento dos processos. Mais recentemente, a crítica surge como elemento central para a prática e o sucesso do conhecimento (Ford, 2015, Longino, 1990, 2002) e revela a predominância, neste contexto, do desenvolvimento do conhecimento epistêmico. Segundo Osborne (2016), estes três tipos de conhecimento, quando considerados e trabalhados de modo conectados, podem contribuir para o desenvolvimento do raciocínio científico.

Para possibilitar aos estudantes o desenvolvimento e o uso de raciocínio científico, o ensino por investigação deve considerar tais conhecimentos por meio das informações e conceitos que os estudantes já tenham trabalhado, dos problemas propostos para a investigação, dos modos de interação dos estudantes com o problema e da análise 
que advém e se sustenta nas interações ocorridas em aula (Carvalho, 2013, Ferraz, \& Sasseron, 2017, Machado, \& Sasseron, 2012, Sasseron, \& Carvalho, 2008). Ao transitar pelas informações por meio da investigação, construindo novos entendimentos sobre as informações que já possuem, e, por meio de análises críticas e constantes das ações, os estudantes estarão desenvolvendo práticas científicas e epistêmicas em estreita relação com o desenvolvimento do raciocínio científico.

Mas quais são os suportes disponibilizados ao professor para favorecer o desenvolvimento de práticas em sala de aula de ciências? O currículo nacional recém proposto expõe elementos que auxiliem o professor nesta tarefa?

\section{A Base Nacional Comum Curricular: fundamentos e estrutura}

Novo documento normativo da educação brasileira, aprovado pelo Conselho Nacional de Educação em dezembro de 2017 e publicado pelo Ministério da Educação no dia 20 do mesmo mês, a Base Nacional Comum Curricular (BNCC) é apresentada como sendo um "conjunto orgânico e progressivo de aprendizagens essenciais que todos os alunos devem desenvolver ao longo das etapas e modalidades da Educação Básica” (MEC, 2017,p. 7, ênfase no original). Importante destacar que o documento publicado traz detalhamentos curriculares para as etapas da Educação Infantil e do Ensino Fundamental, ficando de fora o Ensino Médio, etapa final e concluinte da Educação Básica nacional.

$\mathrm{Na}$ introdução do documento, faz-se menção à LDB e outros marcos legais vigentes que o embasam, ao Plano Nacional de Educação (PNE) de 2014, aos princípios de igualdade, diversidade e equidade, ressaltando também os princípios da Lei Brasileira de Inclusão da Pessoa com Deficiência. Também é destacada a educação integral pela afirmação de que se almeja a formação e o desenvolvimento humano global dos estudantes, em contraposição à priorização do desenvolvimento intelectual ou afetivo.

Outro aspecto importante a se destacar é a menção aos currículos como complementares à BNCC, entendendo que as decisões tomadas para a concretização do currículo é "que vão adequar as proposições da BNCC à realidade local, considerando a autonomia dos sistemas ou das redes de ensino e das instituições escolares, como também o contexto e as características dos alunos" (MEC, 2017, p.16).

Organizada em torno de competências, apresentadas no documento como os conhecimentos, as habilidades, as atitudes e os valores para atuação na vida cotidiana, exercício da cidadania e inserção no mundo do trabalho, logo no início do documento, a BNCC apresenta as etapas da Educação Básica, sob as quais tratará no texto, e como elas estão estruturadas.

Para a etapa da Educação Infantil, o documento apresenta os direitos de aprendizagem e desenvolvimento e os campos de experiências. Para cada um dos três grupos de faixas etárias - 0 a 1 ano e 6 meses; 1 ano e 7 meses a 3 anos e 11 meses; e 4 anos a 5 anos e 11 meses - são descritos os objetivos de aprendizagem e desenvolvimento. Além disso, são anunciadas, para o final da Educação Infantil, as sínteses das aprendizagens 
que se espera que sejam atingidas para cada campo de experiência.

Para a etapa do Ensino Fundamental, a BNCC apresenta as áreas de conhecimento e os componentes curriculares de cada área. Para cada um e todos eles há competências específicas listadas. Para cada componente curricular, e para cada ano escolar, são apresentadas as unidades temáticas, os objetos de conhecimento e as habilidades. São cinco as área de conhecimento do Ensino Fundamental na BNCC e nove os componentes curriculares: Linguagens, composta pelos componentes Língua Portuguesa, Arte, Educação Física e Língua Inglesa; Matemática, componente curricular Matemática; Ciências da Natureza, componente curricular Ciências; Ciências Humanas, componentes curriculares História e Geografia; e Ensino Religioso, componente curricular Ensino Religioso.

\section{As Ciências da Natureza na BNCC}

Na apresentação da área Ciências da Natureza, o letramento científico é destacado como compromisso da área para o Ensino Fundamental. Também é mencionado que o ensino das ciências deva ocorrer na articulação com outros campos de saber e que "precisa assegurar aos alunos do Ensino Fundamental o acesso à diversidade de conhecimentos científicos produzidos ao longo da história, bem como a aproximação gradativa aos principais processos, práticas e procedimentos da investigação científica" (MEC, 2017, p.319, grifo no original).

O processo investigativo é apresentado como sendo um contraponto à realização de tarefas com etapas predefinidas é descrito do seguinte modo:

O processo investigativo deve ser entendido como elemento central na formação dos estudantes, em um sentido mais amplo, e cujo desenvolvimento deve ser atrelado a situações didáticas planejadas ao longo de toda a educação básica, de modo a possibilitar aos alunos revisitar de forma reflexiva seus conhecimentos e sua compreensão acerca do mundo em que vivem. (MEC, 2017, p.320)

Importante destacar que a definição de processo investigativo faz menção ao desenvolvimento contínuo e que este seria o fundamento para o surgimento de reflexões. Preocupamo-nos a ideia que subjaz a esta proposta de que seja o estudante o responsável pelo desenvolvimento da reflexão. A esperança do aparecimento espontâneo da visão crítica e reflexiva é contraditória à própria investigação, como aqui a defendemos, na qual a crítica e a reflexão são elementos fundantes do processo.

Seguindo as ideias expostas na apresentação do processo investigativo, a BNCC afirma que o ensino de Ciências da Natureza deve ocorrer por meio da promoção de situações investigativas em sala de aula em que sejam abordadas quatro modalidades

7 O termo letramento científico é adotado na BNCC e congrega as discussões sobre a polissemia dos objetivos do ensino de ciências expressa também pelos termos alfabetização científica e enculturação científica. Em Sasseron e Carvalho (2011), discutimos esta polissemia e mostramos que, embora com nomes diversos, os intuitos e as ações para alcançar cada um são os mesmos. Por este motivo é que, alinhados ao trabalho mencionado, utilizamos o termo alfabetização científica. 
de ação: definição de problemas; levantamento, análise e representação; comunicação; e intervenção. De modo mais detalhado, o texto nos informa como se caracterizaria cada modalidade de ação:

Definição de problemas: $(1)^{8}$ observar o mundo a sua volta e fazer perguntas; (2) analisar demandas, delinear problemas e planejar investigações; (3) propor hipóteses.

Levantamento, análise e representação: (4) planejar e realizar atividades de campo (experimentos, observações, leituras, visitas, ambientes virtuais etc.); (5) desenvolver e utilizar ferramentas, inclusive digitais, para coleta, análise e representação de dados (imagens, esquemas, tabelas, gráficos, quadros, diagramas, mapas, modelos, representações de sistemas, fluxogramas, mapas conceituais, simulações, aplicativos etc.); (6) avaliar informação (validade, coerência e adequação ao problema formulado); (7) elaborar explicações e/ou modelos; (8) associar explicações e/ou modelos à evolução histórica dos conhecimentos científicos envolvidos; (9) selecionar e construir argumentos com base em evidências, modelos e/ou conhecimentos científicos; (10) aprimorar seus saberes e incorporar, gradualmente, e de modo significativo, o conhecimento científico; (11) desenvolver soluções para problemas cotidianos usando diferentes ferramentas, inclusive digitais.

Comunicação: (12) organizar e/ou extrapolar conclusões; (13) relatar informações de forma oral, escrita ou multimodal; (14) apresentar, de forma sistemática, dados e resultados de investigações; (15) participar de discussões de caráter científico com colegas, professores, familiares e comunidade em geral; (16) considerar contraargumentos para rever processos investigativos e conclusões.

Intervenção: (17) implementar soluções e avaliar sua eficácia para resolver problemas cotidianos; (18) desenvolver ações de intervenção para melhorar a qualidade de vida individual, coletiva e socioambiental. (MEC, 2017, p.321)

Podemos perceber que as modalidades de ação do processo investigativo propostas na BNCC consideram a diversidade de atividades envolta na construção de entendimento sobre os conhecimentos científicos e sobre a própria ciência. Contudo, chama a atenção o grande número de ações voltadas à modalidade Levantamento, análise e representação quando comparado ao número de ações referentes às demais modalidades. Obviamente que o trabalho com tais modalidades e a frequência de seu surgimento em aulas estará sob responsabilidade mais direta do professor da turma, mas a baixa ênfase nas ações voltadas à Definição de problemas e à Intervenção denuncia, de modo implícito uma visão de ensino de ciências cujo protagonismo dos estudantes alia-se mais diretamente ao trabalho para o desenvolvimento de entendimento sobre conhecimentos conceituais das ciências.

Tal suposição pode ser confirmada do ponto de vista teórico com um olhar mais atento para as habilidades listadas no documento para cada objeto de conhecimento.

8 A numeração não está presente no documento original e foi inserida com a finalidade de tornar mais simples à referência a cada ação investigativa ao longo deste texto. 
Buscamos fazer isso analisando-as com base nas discussões sobre as práticas de sala de aula anteriormente apresentadas.

Ainda com referência à apresentação das Ciências da Natureza, as unidades temáticas são Matéria e energia, Vida e evolução e Terra e Universo. No texto da BNCC há menção a que se deva trabalhar as temáticas buscando consolidar relações que expressem temas sobre sustentabilidade ambiental, saúde e tecnologia. Além disso, ao expor as unidades temáticas, o texto destaca que o trabalho com as mesmas deve ocorrer ponderando os objetos de conhecimento e as habilidades a eles relacionadas; e que objetos de conhecimento e habilidades foram construídos considerando a complexificação dos conteúdos pela continuidade dos temas tratados em toda educação básica, portanto estando aí inclusa a Educação Infantil, obrigatória às crianças em seu segmento para a faixa etária de 4 anos a 5 anos e 11 meses de idade.

\section{As práticas científicas e epistêmicas na BNCC: um olhar para as habilidades listadas para os anos iniciais do Ensino Fundamental}

Nosso recorte para a análise escolhe focalizar os cinco anos iniciais do Ensino Fundamental. Nestes anos de escolarização, usualmente as turmas ficam a cargo de um único professor generalista, formado em Pedagogia ou Normal Superior.

Conforme mencionado anteriormente, para cada componente curricular, em cada ano escolar, são apresentadas as unidades temáticas, os objetos de conhecimento e as habilidades. As unidades temáticas das Ciências da Natureza são as mesmas para todo o Ensino Fundamental, mas os objetos de conhecimentos alteram-se, revelando aprofundamento e mudança de foco da discussão sobre a temática de um ano escolar para outro. As habilidades figuram como objetivos a serem desenvolvidos na abordagem dos objetos de conhecimento para aquele ano escolar.

O objetivo do presente texto, conforme anunciando anteriormente, é analisar como as ciências figuram na Base Nacional Comum Curricular. Pretendemos, diante desta análise, discutir como o trabalho em sala de aula pode contribuir para o ensino de ciências que realmente introduza as ciências como corpo de conhecimento nas salas de aula.

Para alcançar tal finalidade, procedemos à análise de cada habilidade associada às Ciências da Natureza exposta para cada um dos cinco anos escolares iniciais do Ensino Fundamental.

Um primeiro olhar para os quadros referentes aos anos escolares permite identificar a quantidade de habilidades que são apresentadas em cada segmento: seis para o 1o ano; oito para o 2o ano; dez para o 3o ano; onze para o 4o ano; e treze para o 50 ano.

Estes números pouco nos esclarecem sobre a inserção das habilidades no currículo de Ciências da Natureza tendo em vista o trabalho de sala de aula. Para aprofundar o conhecimento que temos sobre elas, consideraremos as práticas científicas e as práticas epistêmicas anteriormente apresentadas na análise de cada uma das 48 habilidades 
apresentadas pela BNCC para o ensino de Ciências da Natureza nos cinco anos iniciais do Ensino Fundamental.

Com base nos estudos teóricos, tomamos como práticas científicas: PC1: o trabalho com novas informações, PC2: o levantamento e o teste de hipóteses, e PC3: a construção de explicações e a elaboração de justificativas, limites e previsões das explicações. As práticas epistêmicas são consideradas como: PE1: a proposição de ideias, PE2: a comunicação de ideias, PE3: a avaliação de ideias, e PE4: a legitimação de ideias.

Além disso, a análise das habilidades levou em consideração as quatro modalidades de ações investigativas propostas na BNCC.

Pela leitura de cada uma das habilidades, foi possível classificá-las com referência à apresentação explícita de elementos de práticas científicas e de práticas epistêmicas.

Esta análise foi validada por membros do grupo de pesquisa, em discussões em que as categorias de análise eram apresentadas e as classificações, discutidas, havendo grande concordância. A figura 1 sintetiza esta análise:

\begin{tabular}{|c|c|c|c|c|}
\hline Ano escolar & Habilidade & Práticas científicas & Práticas epistêmicas & Ações investigativas \\
\hline \multirow{6}{*}{1} & EF01CI01 & $\mathrm{PC} 1$ & PE2 & 5,13 \\
\hline & EF01CI02 & PC1, PC3 & PE2 & 5,13 \\
\hline & EF01CI03 & & PE2 & 10,13 \\
\hline & EF01CI04 & PC1 & & 5 \\
\hline & EF01CI05 & PC1 & PE2 & 10,13 \\
\hline & EF01CI06 & PC1 & & 6,10 \\
\hline \multirow{8}{*}{2} & EF02CI01 & PC1 & & 5,10 \\
\hline & EF02CI02 & PC1 & PE1 & $6,11,13$ \\
\hline & EF02CI03 & & PE2 & 10,13 \\
\hline & EF02CI04 & PC3 & PE2 & 10,13 \\
\hline & EF02CI05 & $\mathrm{PC} 1, \mathrm{PC} 2, \mathrm{PC} 3$ & PE3 & $3,4,5,7,10,12,14$ \\
\hline & EF02CI06 & PC1 & PE3 & $7,10,13$ \\
\hline & EF02CI07 & PC1 & PE2 & $7,10,13$ \\
\hline & EF02CI08 & PC1 & & 5,10 \\
\hline \multirow{10}{*}{3} & EF03CI01 & PC1 & PE3 & 5,10 \\
\hline & EF03CI02 & PC1 & PE2 & $5,10,13$ \\
\hline & EF03CI03 & $\mathrm{PC1}$ & PE2 & $6,10,13,15$ \\
\hline & EF03CI04 & $\mathrm{PC1}$ & & 10 \\
\hline & EF03CI05 & PC1 & PE2 & 10,13 \\
\hline & EF03CI06 & $\mathrm{PC} 1$ & & 5 \\
\hline & EF03CI07 & $\mathrm{PC} 1$ & & 5,10 \\
\hline & EF03CI08 & PC1 & PE2 & $5,10,13$ \\
\hline & EF03CI09 & PC1 & & 5 \\
\hline & EF03CI10 & PC1, PC3 & & $5,7,10$ \\
\hline
\end{tabular}

Figura 1. Síntese da análise realizada para as habilidades de Ciências da Natureza dos cinco anos iniciais do Ensino Fundamental presentes na BNCC (continua) 


\begin{tabular}{|c|c|c|c|c|}
\hline Ano escolar & Habilidade & Práticas científicas & Práticas epistêmicas & Ações investigativas \\
\hline \multirow{11}{*}{4} & EF04CI01 & PC1, PC3 & & $5,7,10$ \\
\hline & EF04CI02 & PC1 & PE2 & 5,13 \\
\hline & EF04CI03 & PC1, PC3 & & 7,10 \\
\hline & EF04CI04 & $\mathrm{PC1}$ & PE3 & $5,7,13$ \\
\hline & EF04CI05 & $\mathrm{PC} 1$ & PE2 & 10,13 \\
\hline & EF04CI06 & PC1, PC3 & & 7,10 \\
\hline & EF04CI07 & $\mathrm{PC} 1$ & & 10 \\
\hline & EF04CI08 & PC1 & PE1 & $5,10,11$ \\
\hline & EF04CI09 & $\mathrm{PC} 1$ & & 5 \\
\hline & EF04CI10 & PC1 & & 5 \\
\hline & EF04CI11 & $\mathrm{PC} 1$ & & 5,10 \\
\hline \multirow{13}{*}{5} & EF05CI01 & PC1 & & 5,6 \\
\hline & EF05CI02 & PC1, PC3 & PE3 & $5,6,10$ \\
\hline & EF05CI03 & PC1 & PE3 & 6,10 \\
\hline & EF05CI04 & PC1 & PE1, PE2 & $5,10,11,13$ \\
\hline & EF05CI05 & & PE1 & 10,11 \\
\hline & EF05CI06 & $\mathrm{PC1}$ & PE3 & 6,10 \\
\hline & EF05CI07 & PC3 & & 7 \\
\hline & EF05CI08 & PC1 & PE1 & 10,11 \\
\hline & EF05CI09 & & PE2 & 13,14 \\
\hline & EF05CI10 & $\mathrm{PC} 1$ & & 10 \\
\hline & EF05CI11 & PC3 & & 5,10 \\
\hline & EF05CI12 & $\mathrm{PC} 1, \mathrm{PC} 3$ & PE3 & $5,6,7,10$ \\
\hline & EF05CI13 & & PE1, PE2 & $11,13,15$ \\
\hline
\end{tabular}

Figura 1. Síntese da análise realizada para as habilidades de Ciências da Natureza dos cinco anos iniciais do Ensino Fundamental presentes na BNCC (continuação)

As informações contidas neste quadro precisam ser analisadas com cautela. Elas não são o ensino que será oferecido em sala de aula e exprimem apenas uma análise das habilidades que são descritas na BNCC para o ensino das Ciências da Natureza nos cinco primeiros anos do Ensino Fundamental. Utilizando sua autonomia como docente, o professor deverá inserir outras ações e estratégias para o desenvolvimento de tais habilidades, podendo, inclusive, trabalha-las de modo conectado entre si e com as habilidades descritas para os outros componentes curriculares.

A análise das habilidades considerando as práticas científicas e as práticas epistêmicas nos permite fazer afirmações importantes. Uma primeira observação revela que as práticas científicas aparecem com maior frequência se comparadas às práticas epistêmicas. Há apenas 5 habilidades dentre as 48 existentes em relação às quais não identificamos práticas científicas. Por outrolado, as práticas epistêmicas surgem associadas a 28 habilidades, o que implica que não encontramos práticas epistêmcias associadas a 
20 das habilidades da BNCC. Outra observação é a de que somente 23 habilidades estão associadas a práticas científicas e práticas epistêmicas conjuntamente. Lembramos que segundo Jiménez-Aleixandre e Crujeiras (2017), o ensino de ciências nos dias atuais, visando à alfabetização científica, deveria cuidar para que estas práticas ocorressem concomitantemente de modo mais frequente. Esta ocorrência conjunta poderia permitir que os estudantes tivessem um contato mais direto com o processo de investigação, realizando as práticas que o caracterizam e aprendendo os conceitos das ciências juntamentecommodos deorganizar,avaliar, divulgarelegitimarconhecimentosnestaárea.

As informações da Figura 1 nos permitem perceber também a alta incidência de PC1, a prática científica associada à obtenção de nova informação. Entre as 48 habilidades listadas, 40 se relacionam a este tipo de prática científica, havendo 14 habilidades associadas apenas à PC1, sem associação com outras práticas científicas ou epistêmicas. Este dado sinaliza que, apesar de a área de pesquisa em ensino de ciências apontar a importância de que as aulas levem os estudantes a ter contato com mais aspectos das ciências além dos seus conceitos, o fomento à apresentação de informações é predominante no documento curricular nacional. Pode ser levantada a suposição de que estes dados se referem, majoritariamente, aos três anos iniciais do Ensino Fundamental, quando poderia ser esperada a apresentação mais frequente de novas informações aos estudantes. Contudo, os números mostram que isso não se sustenta, uma vez que para os 3 o e 40 anos, todas as habilidades listadas se relacionam à PC1, para o 1o ano, das 6 habilidades listadas, 5 estão associadas à PC1, para o 2o ano, das 8 habilidades, 6 associam-se à PC1 e para o 5o ano, 8 das 13 habilidades estão associadas à PC1. Além disso, se a hipótese de que apenas nos três anos iniciais houvesse maior trabalho com informações, haveria uma incoerência no documento da BNCC, pois o texto faz menção ao Ensino Fundamental como uma continuidade da Educação Infantil e, portanto, muitas das informações poderiam ter sido trabalhadas na etapa anterior da escolarização das crianças.

Considerando as práticas epistêmicas, é digno de nota que não associamos PE4, a legitimação das ideias, a nenhuma das 48 habilidades listadas. Voltamos a insistir que isso talvez ocorra no trabalho cotidiano do professor com seus alunos, referendando ideias propostas, analisadas e sistematizadas em sala de aula. No entanto, este fato parece pouco coerente com a intenção do ensino de Ciências da Natureza apresentado na BNCC que anuncia prezar pela complexificação dos temas por sua abordagem contínua ao longo da formação dos estudantes; o que implicaria na necessidade de retomada de ideias e de legitimação dos entendimentos construídos.

Também chama a atenção o fato de PE3, a avaliação de ideias ter sido associada a apenas 8 habilidades. O processo de avaliação é central e crítico para o desenvolvimento das ciências e, portanto, seria esperado que tivesse mais destaque, a fim de que pudesse ser constantemente realizado por professor e alunos em suas interações com os temas das ciências em sala de aula.

De mesmo modo, a associação das habilidades à prática epistêmica proposição de 
ideias (PE1) teve incidência baixa, sendo identificada em apenas 6 habilidades. Isso revela que os textos das habilidades listadas na BNCC não favorecem a promoção de situações em que os estudantes possam se envolver com atividades que gerem à proposição de ideias, medidas ou de artefatos, produtos do trabalho intelectual que pode ser realizado em sala de aula.

Dentre as práticas epistêmicas, a mais frequente é PE2, a comunicação de ideias. Ela está associada a 16 das 48 habilidades apresentadas. Sua incidência é mais alta nos três anos iniciais do Ensino Fundamental e isso pode estar relacionado ao momento da formação dos estudantes e, em especial, ao desenvolvimento de sua alfabetização em língua materna, sendo sua ocorrência privilegiada na busca por auxiliar os estudantes neste processo. De todo modo, as ciências se sustentam na divulgação de ideias construídas e, portanto, independentemente da etapa da escolarização, seria recomendado que os alunos pudessem bem desenvolver suas práticas de comunicação, avançando em modos de explicitação de argumentos para além da produção de registros gráficos tão importantes, mas já tão desenvolvida.

A leitura das habilidades revela ainda haver aquelas que tratam de processos mais complexos e outras mais simples para todos os anos analisados. Isso pode ser um interessante indício da preocupação da proposta em balancear a apresentação dos temas ao longo de cada ano escolar. No entanto, não conseguimos em nossa análise identificar uma tendência de complexificação que mostraria como a continuidade enunciada estaria sendo atendida.

No que diz respeito às modalidades de ações de investigação, as informações contidas na Figura 1 revelam uma maior frequência de ações relacionadas ao levantamento, análise e representação, em especial a ação (10) aprimorar seus saberes e incorporar, gradualmente, e de modo significativo, o conhecimento científico, presente em 34 das 48 habilidades, evidenciado a tendência do documento em se preocupar com a apresentação de conteúdos novos aos estudantes, e a ação (5) desenvolver e utilizar ferramentas, inclusive digitais, para coleta, análise e representação de dados (imagens, esquemas, tabelas, gráficos, quadros, diagramas, mapas, modelos, representações de sistemas, fluxogramas, mapas conceituais, simulações, aplicativos etc.), presente em 25 das 48 habilidades, associada, na maioria dos casos, a ideias que demandem a análise e representação de informações já mencionadas na própria habilidade. Com frequência um pouco mais baixa (19 associações nas 48 habilidades) é observada a ação de comunicação (13) relatar informações de forma oral, escrita ou multimodal e isso parece revelar mais uma vez a tendência da BNCC de dar atenção, não somente na área de Linguagens, para a alfabetização dos estudantes em língua materna.

É digno de nota que o trabalho com as modalidades de ações investigativas definição de problemas foram identificadas em apenas uma habilidade e as ações relacionadas à modalidade intervenção não foram encontradas nesta nossa análise. Estes dados merecem ser considerados com cautela, pois as ciências são reconhecidas por seu caráter investigativo sustentado pela constituição de problemas a ser analisados e a 
relação dos mesmo com as intervenções decorrentes na sociedade ou no ambiente. Assim, podemos afirmar que a BNCC se ocupa de modo mais intenso com determinadas ações e práticas das ciências, enquanto outras, igualmente importantes e necessárias de serem trabalhadas em sala de aula, ficam à margem do texto. Este fato explicita a intenção ou a preocupação mais frequente em que os estudantes apliquem conhecimentos de modo imediato, exibindo a estrita relação entre os conhecimentos das disciplinas escolares e conhecimentos da experiência cotidiana sem explorar modos com os quais os estudantes possam travar contato mais direto com os conhecimentos do primeiro tipo.

As informações contidas na Figura 1 ainda revelam que das 18 ações investigativas listadas pela BNCC para o ensino de Ciências da Natureza, 7 não foram encontradas na análise das habilidades dos cinco anos iniciais do Ensino Fundamental. As ações investigativas não identificadas foram: (1) observar o mundo a sua volta e fazer perguntas; (2) analisar demandas, delinear problemas e planejar investigações; (8) associar explicações e/ou modelos à evolução histórica dos conhecimentos científicos envolvidos; (9) selecionar e construir argumentos com base em evidências, modelos e/ ou conhecimentos científicos; (16) considerar contra-argumentos para rever processos investigativos e conclusões; (17) implementar soluções e avaliar sua eficácia para resolver problemas cotidianos e (18) desenvolver ações de intervenção para melhorar a qualidade de vida individual, coletiva e socioambiental.

Isso nos parece muito preocupante, pois significa que as 48 habilidades apresentadas para este momento da escolarização não são capazes de atender a todas as ações de investigação que se espera desenvolver entre os estudantes. Entendemos que, muitas, se não todas, destas ações não encontradas nesta análise podem surgir no trabalho do professor em sala de aula, a partir do estabelecimento de estratégias que permitam outros modos de investigação além daqueles relacionados às habilidades.

Contudo, é digno ressaltar que, embora mencionadas como ações de investigação a serem trabalhadas no Ensino Fundamental, algumas delas não foram associadas às habilidades expressas na BNCC. Além de termos detectado especial ausência de ações associadas à identificação e constituição de problema a ser investigado e à tomada de decisões e construção de modos de interagir com os conhecimentos aprendidos para além do contexto escolar.

$\mathrm{Na}$ expectativa de esmiuçar um pouco mais o que é trazido pelas habilidades listadas na BNCC para a abordagem das Ciências da Natureza nos cinco primeiros do Ensino Fundamental, destacamos e avaliamos mais detidamente algumas destas habilidades.

Começamos por trazer dois exemplos do 1o ano do Ensino Fundamental:

EF01CI01 - Comparar características de diferentes materiais presentes em objetos de uso cotidiano, discutindo sua origem, os modos como são descartados e como podem ser usados de forma mais consciente.

Nesta habilidade, são exigidas duas principais atividades: comparar características de materiais e discutir a origem de objetos, seu descarte e modos de uso mais conscientes. 
O trabalho com esta habilidade pode se estender por várias semanas, começando com os estudantes tendo acesso a novas informações e comparando-as (PC1) e discutindo as características, os usos e o descarte dos objetos bem como modos mais sustentáveis de consumo (PE2). Trata-se, portanto, do trabalho com informações e dados que se complexifica ao longo do processo, sempre mantendo o foco no tema da unidade Matéria e energia. Podemos perceber também que esta habilidade se relaciona a duas modalidades de ações investigativas distintas: o levantamento, análise e representação, representado pela ação (5) desenvolver e utilizar ferramentas, inclusive digitais, para coleta, análise e representação de dados (imagens, esquemas, tabelas, gráficos, quadros, diagramas, mapas, modelos, representações de sistemas, fluxogramas, mapas conceituais, simulações, aplicativos etc.), a comunicação, por meio da ação de (13) relatar informações de forma oral, escrita ou multimodal.

Com isso, percebemos que esta é uma habilidade complexa, por unir diversas modalidades de ações investigativas, além de congregar práticas científicas e epistêmicas.

Para o mesmo ano escolar, em relação à unidade temática Terra e Universo, é proposta a habilidade EF01CI05 - Identificar e nomear diferentes escalas de tempo: os períodos diários (manhã, tarde, noite) e a sucessão de dias, semanas, meses e anos. Esta habilidade exige que os alunos tenham contato com informações (PC1) de modo a perceber as diferenças entre passagens de tempo e, ao solicitar nomeação de escalas de tempo, associa-se à comunicação de ideias (PE2). Ela traz, ainda, a possibilidade de trabalho com duas modalidades de ações investigativas: o levantamento, análise e representação, com o surgimento da ação (10) aprimorar seus saberes e incorporar, gradualmente, e de modo significativo, o conhecimento científico e a comunicação, representada pela ação (13) relatar informações de forma oral, escrita ou multimodal, e a intervenção. Isso nos leva a entender que é uma habilidade mais simples do que a elencada anteriormente e, possivelmente, alguns alunos já terão conhecimento sobre o tema, sobretudo porque o mesmo faz parte das aprendizagens $s^{9}$ que são esperadas de serem atingidas pelas crianças ao final da Educação Infantil para sua transição ao Ensino Fundamental.

Outra habilidade para a qual chamamos a atenção está elencada no 20 ano:

EF02CI08 - Comparar o efeito da radiação solar (aquecimento e reflexão) em diferentes tipos de superfície (água, areia, solo, superfícies escura, clara e metálica etc.).

Neste caso, o trabalho dos estudantes deverá ocorrer pela obtenção de novas informações sobre a radiação solar e a comparação entre as mesmas (PC1). Dentre as modalidades de ações investigativas, identificamos as ações (5) desenvolver e utilizar ferramentas, inclusive digitais, para coleta, análise e representação de dados (imagens, esquemas, tabelas, gráficos, quadros, diagramas, mapas, modelos, representações de sistemas, fluxogramas, mapas conceituais, simulações, aplicativos etc.) e (10) aprimorar

9 Na seção de Educação Infantil da BNCC, campo de experiência Espaços, tempos, quantidades, relações e transformações, entre as aprendizagens esperadas ao final deste ciclo, figura: "Utilizar unidades de medida (dia e noite; dias, semanas, meses e ano) e noções de tempo (presente, passado e futuro; antes, agora e depois), para responder a necessidades e questões do cotidiano" (MEC, 2017, p.53). 
seus saberes e incorporar, gradualmente, e de modo significativo, o conhecimento científico. Uma pequena alteração no modo de redação desta habilidade poderia favorecer uma maior complexidade no trabalho, contribuindo para a promoção de condições para que os estudantes pudessem exercer sua autonomia intelectual de modo mais efetivo. Isso poderia ocorrer caso a habilidade fosse redigida como Investigar o efeito da radiação solar em diferentes superfícies. Neste caso, não apenas a comparação seria manifestada, mas sobretudo poderia ser privilegiado o trabalho com a análise de como a radiação solar afeta diferentes materiais e como a radiação solar pode ser mais ou menos intensa a depender do horário em que é observada ou das condições climáticas do momento da observação. Isso poderia implicar no trabalho com práticas epistêmicas associadas à comunicação (PE2) e à avaliação de ideias (PE3), além do envolvimento com a definição de problemas, por meio da ação (2) analisar demandas, delinear problemas e planejar investigações.

Pode ser dito que nesta idade (crianças do 2o ano do Ensino Fundamental têm entre 7 e 8 anos de idade), seria prudente não solicitar algo tão complexo dos alunos. Contudo, no próprio 20 ano está listada uma habilidade que solicita o uso de práticas semelhantes ao novo modo proposto: EF02CI05 - Investigar a importância da água e da luz para a manutenção da vida de plantas em geral.

No 3o ano, está elencada uma habilidade que também parece não privilegiar o desenvolvimento de investigação pelos estudantes:

EF03CI02 - Experimentar e relatar o que ocorre com a passagem da luz através de objetos transparentes (copos, janelas de vidro, lentes, prismas, água etc.), no contato com superfícies polidas (espelhos) e na intersecção com objetos opacos (paredes, pratos, pessoas e outros objetos de uso cotidiano).

A ideia de experimentar e relatar pode promover autonomia dos estudantes no desenvolvimento das investigações por meio do trabalho com novas informações (PC1) e a comunicação das ideias aos colegas (PE2). Contudo, todos os elementos para a análise já estão elencados, o que pode suscitar uma discussão em que o foco se torna apenas a diferenciação de objetos transparentes, polidos e opacos, não oferecendo oportunidades para a avaliação de porque a passagem da luz ocorrer de modo diferente em cada um deles. Nesta habilidade, percebemos que as modalidades de ações investigativas suscitadas são, como em outros casos, as ações (5) desenvolver e utilizar ferramentas, inclusive digitais, para coleta, análise e representação de dados (imagens, esquemas, tabelas, gráficos, quadros, diagramas, mapas, modelos, representações de sistemas, fluxogramas, mapas conceituais, simulações, aplicativos etc.), (10) aprimorar seus saberes e incorporar, gradualmente, e de modo significativo, o conhecimento científico e (13) relatar informações de forma oral, escrita ou multimodal.

No 40 ano, encontramos habilidades que demonstram preocupação com o aprofundamento de temas já trabalhados em anos anteriores, algo enunciado no texto introdutório das Ciências da Natureza na BNCC: 
EF04CI04 - Analisar e construir cadeias alimentares simples, reconhecendo a posição ocupada pelos seres vivos nessas cadeias e o papel do Sol como fonte primária de energia na produção de alimentos.

EF04CI08 - Propor, a partir do conhecimento das formas de transmissão de alguns microrganismos (vírus, bactérias e protozoários), atitudes e medidas adequadas para prevenção de doenças a eles associadas.

Nosso entendimento de que o aprofundamento de ideias sobre cadeias alimentares e sobre microrganismos possa ocorrer encontra respaldo no fato de que as duas habilidades remetem ao reconhecimento, pelos alunos, de algo como fundamento para a concretização da mesma. No caso de EF04CI04, a análise do processo, considerando os fatores mencionados, permite o desenvolvimento de PE3, a avaliação de ideias. A construção de cadeias alimentares surge como um desdobramento de tal avaliação a partir do trabalho com informações disponibilizadas (PC1). Neste caso, além do possível desenvolvimento da ação (5) desenvolver e utilizar ferramentas, inclusive digitais, para coleta, análise e representação de dados (imagens, esquemas, tabelas, gráficos, quadros, diagramas, mapas, modelos, representações de sistemas, fluxogramas, mapas conceituais, simulações, aplicativos etc.) e da ação (10) aprimorar seus saberes e incorporar, gradualmente, e de modo significativo, o conhecimento científico, também parece haver oportunidade para o desenvolvimento de (7) elaborar explicações e/ou modelos, uma vez que a análise das informações tende a gerar explicações ou modelos.

Em EF04CI08, o conhecimento sobre formas de transmissão de microrganismos (PC1) é essencial para a proposição de modos de agir (PE1). Este trabalho requer que os alunos possam (5) desenvolver e utilizar ferramentas, inclusive digitais, para coleta, análise e representação de dados (imagens, esquemas, tabelas, gráficos, quadros, diagramas, mapas, modelos, representações de sistemas, fluxogramas, mapas conceituais, simulações, aplicativos etc.), além de associar-se à necessidade de (10) aprimorar seus saberes e incorporar, gradualmente, e de modo significativo, o conhecimento científico e de (11) desenvolver soluções para problemas cotidianos usando diferentes ferramentas, inclusive digitais.

É digno de nota que estas duas habilidades destacadas podem ser associadas a práticas científicas e epistêmicas. Para isso, a fim de que seja exitoso, o trabalho com as mesmas precisa ocorrer de modo conjunto, algo já destacado por Jiménez-Aleixandre e Crujeiras (2017) como importante para a promoção da alfabetização científica.

Outras habilidades que destacamos aparecem no 50 ano:

EF05CI03 - Selecionar argumentos que justifiquem a importância da cobertura vegetal para a manutenção do ciclo da água, a conservação dos solos, dos cursos de água e da qualidade do ar atmosférico.

EF05CI06 - Selecionar argumentos que justifiquem por que os sistemas digestório e respiratório são considerados corresponsáveis pelo processo de nutrição do organismo, com base na identificação das funções desses sistemas.

Estas habilidades aparentam complexidade na demanda por fazerem menção 
à seleção de argumentos que justifiquem algo. Tal atividade centra-se em buscar uma informação dentre muitas que podem ser ofertadas, o que caracteriza a tarefa como relacionada à obtenção e uso de informação (PC1) e à avaliação da mesma (PE3). Também podemos identificar que estas habilidades permitem o desenvolvimento da modalidade de ações investigativas levantamento, análise e representação, a partir do envolvimento com as ações (6) avaliar informação (validade, coerência e adequação ao problema formulado) e (10) aprimorar seus saberes e incorporar, gradualmente, e de modo significativo, o conhecimento científico. No entanto, a ideia de desenvolvimento de argumentação, que parece subsidiar estas habilidades, não está explícita, uma vez que não se faz menção aos processos para construção de argumentos e de suas justificativas o que, de fato, embasaria o desenvolvimento da argumentação (Erduran, \& JiménezAleixandre, 2006).

\section{Considerações finais}

É importante ressaltar uma vez mais que este artigo não tem a finalidade de contestar o documento curricular nacional recém-publicado. Entendemos que a BNCC é um parâmetro para a construção do planejamento anual e diário das aulas e, aos professores, cabe o exercício de sua autonomia para conciliar a proposta do Ministério da Educação com a realidade de sua sala de aula e de seus estudantes.

Ressaltamos que a atenção ao trabalho com práticas científicas e epistêmicas no ensino de ciências surge em outros países; em especial, nos Estados Unidos da América, aparece como decorrência das leituras críticas que têm sido feitas ao NGSS. Nesta perspectiva, Osborne (2014) expressa a importância de que as práticas sejam consideradas como forma de possibilitar que as ciências apresentadas em sala de aula melhor representem os entendimentos atuais que se possui sobre a natureza das ciências, considerando aspectos sociais e culturais.

Como destacado anteriormente, a própria BNCC, em seu texto introdutório, faz questão de afirmar que o currículo deve ser complementar às ideias expostas no documento. Nesse sentido, a análise aqui feita pode servir de subsídio para a avaliação e consideração de quais elementos do ensino de Ciências da Natureza precisam receber atenção nos momentos em que a proposta curricular começa a se transformar em planejamento, em atividades e em aulas.

Um aspecto central revelado por esta análise indica a necessidade de atenção ao desenvolvimento das práticas científicas e epistêmicas, bem como das modalidades de ação investigativas, como forma de garantir que o ensino de Ciências da Natureza aborde mais do que apenas fatos das ciências, contribuindo para a ampliação do conhecimento dos estudantes sobre a área, suas atividades e as relações que as mesmas têm com a sociedade, além de poder promover o desenvolvimento de autonomia intelectual dos alunos.

Nossos fundamentos teóricos mostram alterações que o ensino de ciências vem sofrendo em todo o mundo nas últimas décadas, e uma clara mudança de foco no 
processo de ensino em que a aprendizagem dos conteúdos torna-se uma aprendizagem que inclua práticas científicas e epistêmicas pela promoção de participação ativa e intelectual dos estudantes. Deste modo, espera-se que os alunos possam construir não apenas o entendimento dos conteúdos, mas também, e especialmente, conhecimentos sobre a própria ciência, as influências mútuas entre ciência e sociedade e os modos de construir conhecimentos científicos. Isso poderia contribuir, junto ao ensino das demais disciplinas e áreas de conhecimento, para que os estudantes tenham uma visão mais ampla sobre a humanidade, que os capacite a tomar decisões de modo mais consciente e crítico.

Entendemos que uma grande contribuição advinda das Ciências da Natureza para tal empreitada esteja associada ao próprio fazer científico e a sua característica de organização que é, ao mesmo tempo, disciplinada e criativa. Isso requer que modos de agir e pensar sejam avaliados a todo momento, considerando variáveis e entorno, e, em sendo o caso, reajustados e redefinidos. Neste processo, conhecimentos conceituais, procedimentais e epistêmicos fundamentam a reflexão e constituem a base para o desenvolvimento do pensamento científico (Osborne, 2016).

O trabalho contínuo e conjunto com as práticas científicas e as práticas epistêmicas possibilita que elementos da atividade científica sejam desenvolvidos em sala de aula, em especial a investigação e a divulgação das ideias. Isso, pode contribuir para o envolvimento mais ativo e autoral dos estudantes com o aprendizado das ciências. Contudo, nossa análise revelou que as ações de investigação listadas na BNCC são pouco presentes no contexto das habilidades elencadas para os cinco anos iniciais do Ensino Fundamental.

Em alguns casos, entendemos que a investigação não esteja claramente exposta na habilidade por se tratar de uma redação pouco propícia. É o caso, por exemplo, de EF05CI01 - Explorar fenômenos da vida cotidiana que evidenciem propriedades físicas dos materiais - como densidade, condutibilidade térmica e elétrica, respostas a forças magnéticas, solubilidade, respostas a forças mecânicas (dureza, elasticidade etc.), entre outras. Ainda que o verbo explorar possa remeter à investigação, a redação pouco especifica sobre o que deva ser explorado. Deste modo, pode haver casos em que a exploração se dê como uma observação, como a apresentação do conteúdo pelo professor e até mesmo pela atuação ativa dos estudantes na investigação de características físicas de materiais e de fatores que condicionam ou contribuem para fenômenos observados.

Todas estas observações construídas ao longo deste texto apontam para uma necessidade urgente e constante: a formação dos professores.

No texto introdutório geral da BNCC, há menções à formação de professores, e isso aparece na expectativa de que a mesma ocorra em alinhamento com o que está proposto no documento curricular. Uma das ações listadas para a adequação da BNCC às realidades locais aparece como a necessidade de "criar e disponibilizar materiais de orientação para os professores, bem como manter processos permanentes de formação docente que possibilitem contínuo aperfeiçoamento dos processos de ensino 
e aprendizagem" (MEC, 2017, p.17). Isso remete a uma meta do PNE, Plano Nacional de Educação, publicado em 2014, que fazia menção à importância de prover formação inicial e contínua aos professores do Brasil. Contudo, não encontramos no texto da BNCC qualquer diretriz mais específica sobre os moldes que poderiam fundamentar esta formação para além da referência ao próprio texto curricular.

Parece-nos premente que, considerando o que está exposto na BNCC e o que trazemos nesta análise, tais processos formativos considerem os inúmeros estudos realizados na área de pesquisa em ensino de ciências, bem como as experiências e expectativas dos professores e alunos da educação nacional.

No que diz respeito ao ensino das Ciências da Natureza, percebemos claramente a ênfase pouco efetiva na promoção da investigação, embora ela tenha sido mencionada como um dos elementos estruturantes da proposta curricular. Deste modo, é esperado que os processos de formação de professores possam atender a este tema, de forma que eles possam analisar e produzir materiais didáticos adequados para que a investigação científica e as práticas que a acompanham e a caracterizam sejam trabalhadas.

\section{Agradecimentos}

Agradeço aos pareceristas pelas sugestões no momento da revisão, à Professora Cláudia Galian por ter lido e discutido a primeira versão deste texto e aos colegas do LaPEF pelas importantes discussões que, cada uma a seu modo, representaram contribuições para esta versão.

\section{Referências}

Berland, L. K., \& Hammer, D. (2012). Framing for scientific argumentation. Journal of Research in Science Teaching, 49(1), p. 69-84.

Bybee, R. W., \& DeBoer, G. E. (1994). Research on Goals for the Science Curriculum, In Gabel, D. L. (ed.), Handbook of Research in Science Teaching and Learning (p. 357-387). New York, NY: McMillan.

Carvalho, A. M. P. (2013) Ensino de Ciências e a proposição de sequências de ensino investigativas. In Carvalho, A. M. P. (Org.). Ensino de Ciências por Investigação: condições para implementação em sala de aula. (pp. 1-20). São Paulo, SP: Cengage Learning.

Chervel, A. (1990). História das disciplinas escolares: reflexões sobre um campo de pesquisa. Teoria \& Educação, 2, 177-229.

Dewey, J. (1971). Experiência e educação, São Paulo: Nacional.

Duschl, R. A. (2008). Science education in three-part harmony: balancing conceptual, epistemic and social learning goals. Review of Research in Education, 32(1), p. 268-291. 
Ferraz, A. T., \& Sasseron, L. H. (2017). Espaço interativo de argumentação colaborativa: condições criadas pelo professor para promover argumentação em aulas investigativas. Ensaio Pesquisa em Educação em Ciências, 19, p. 1-25. Recuperado de http://dx.doi. org/10.1590/1983-21172017190117.

Ford, M. J. (2015). Educational implications of choosing "practice" to describe Science in Next Generation of Science Standards. Science Education, 99(5), p. 1041-1048.

Fourez, G. (1994). Alphabétisation Scientifique et Technique - Essai sur les finalités de l’enseignement des sciences. Bruxelas, Bélgica: DeBoeck-Wesmael.

Freiberg, H. L. (2015). Dissertação (Mestrado em Educação), Elementos catalisadores para a promoção da negociação de sentidos. Universidade de São Paulo, São Paulo, SP.

Freire, P. (1967). Educação como prática da liberdade. Rio de Janeiro, RJ: Paz e Terra.

Hurd, P. D. (1998). Scientific literacy: new minds for a changing world. Science Education, 82(3), p. 407-416.

Jiménez-Aleixandre, M. P., \& Crujeiras, B. (2017) Epistemic practices and scientific practices in science education. In Taber, K. S, \& Akpan, B. (Eds.). Science Education: an International Course Companion, p. 69-80.

Kelly, G. J. (2008). Inquiry, activity and epistemic practice. In Duschl, R. A., \& Grandy, R. E. (Eds.), Teaching Scientific Inquiry: recommendations for research and implementation (p. 288-291). Rotterdam, Holand: Taipei Sense Publishers.

Knorr-Cetina, K. (1999) Epistemic cultures. Princeton: Princeton University Press.

Latour, B., \& Woolgar, S. (1986). Laboratory life: the construction of scientific facts. Princenton: Princeton University Press.

Longino, H. E. (1990). Science as social knowledge: values and objectivity in science inquiry. Princeton: Princeton University Press.

Longino, H. E. (2002). The fate of knowledge. Princeton: Princeton University Press,.

Machado, V. F., \& Sasseron, L. H. (2012). As perguntas em aulas investigativas de ciências: a construção teórica de categorias. Revista Brasileira de Pesquisa em Educação em Ciências, 12(1), p. 29-44.

MEC, Ministério da Educação (2017). Base Nacional Comum Curricular, Brasília: Secretaria da Educação Básica.

Osborne, J. (2014). Teaching Scientific Practices: Meeting the Challenge of Change, Journal of Science Teacher Education, 25(2), 177-196, doi: 10.1007/s10972-014-9384-1

Osborne, J. (2016). Defining a knowledge base for reasoning in Science: the role of procedural and epistemic knowledge. In Duschl, R. A., \& Bismarck, A. S. (eds.), Reconceptualizing STEM Education: the central role of practice. New York, NY: Routledge. 
Pickering, A. (1992). Science as practice and culture, Chicago: University of Chicago Press.

Sasseron, L. H., \& Carvalho, A. M. P. (2008). Almejando a Alfabetização Científica no Ensino Fundamental: a proposição e a procura de indicadores do processo, Investigações em Ensino de Ciências, 13(3), p.333-352.

Sasseron, L. H. (2015). Alfabetização Científica, ensino por investigação e argumentação: relações entre ciências da natureza e escola, Ensaio Pesquisa em Educação em Ciências, 17(no. Especial), p.49-67.

Solino, A. P. (2017). Tese (Doutorado em Educação), Problemas potenciais significadores em aulas investigativas: contribuições da perspectiva histórico-cultural. Universidade de São Paulo. São Paulo, SP.

Souza, T. N. (2015). Dissertação (Mestrado em Ensino de Ciências), Engajamento disciplinar produtivo e o ensino por investigação: estudo de caso em aulas de Física no Ensino Médio. Universidade de São Paulo, São Paulo, SP.

Stroupe, D. (2015). Describing "Science Practice" in Learning Settings, Science Education, 99(5), p. 1033-1040.

Stroupe, D. (2014). Examining Classroom Science Practice Communities: How Teachers and Students Negotiate Epistemic Agency and Learn Science-as-Practice. Science Education, 98(3), p. 487-516.

Windschitl, M., Thompson, J., \& Braaten, M. (2008). Beyond the scientific method: Model-Based Inquiry as a new paradigm of preference for school science investigations. Science Education, 92(5), p. 941-967.

Young, M. (2007). Para que servem as escolas?, Educação e Sociedade, 28(101), p. 12871302.

Lúcia Helena Sasseron

${ }^{\oplus}$ http://orcid.org/0000-0001-5657-9590

Universidade de São Paulo

Faculdade de Educação

Departamento de Metodologia de Ensino e Educação Comparada

São Paulo, Brasil

sasseron@usp.br

Submetido em 29 de Janeiro de 2018

Aceito em 02 de Julho de 2018

Publicado em 26 de Julho de 2018 